\title{
Hypoxic Injury to Developing Glial Cells: Protective Effect of High Glucose
}

\author{
DAVID J. CALLAHAN, MICHAEL J. ENGLE, AND JOSEPH J. VOLPE
}

Departments of Pediatrics [D.J.C., M.J.E., J.J.V.], Neurology [J.J.V.], and Biochemistry and Molecular Biophysics [J.J.V.], Washington University School of Medicine, St. Louis, Missouri 63110

\begin{abstract}
Hypoxic injury to differentiating glial cells is a critical event in the development of periventricular leukomalacia, the major hypoxic-ischemic lesion of the premature infant. This study has addressed the effects of hypoxia on differentiating glial cells, primarily astrocytes. Primary cultures of dissociated newborn rat brain, which are composed predominantly of differentiating astroglia, were used. Efflux of lactate dehydrogenase, an enzyme enriched in astroglia, was used to quantitate cellular injury. Three major findings are reported. First, differentiating astrocytes were resistant to hypoxic injury for many hours, although by $24 \mathrm{~h}$ of hypoxia severe cellular injury (lactate dehydrogenase efflux of $86 \%$ of total and morphologic changes) was obvious. Second, increase of glucose in the culture medium from the approximately physiological concentration of 5.6 to $15 \mathrm{mM}$ had a marked protective effect versus hypoxia, i.e. lactate dehydrogenase efflux was totally prevented during $24 \mathrm{~h}$ of hypoxia in $15 \mathrm{mM}$ glucose. Third, the protective effect of high glucose appeared to be related to increased utilization by glycolysis, because there was a direct correlation between the resistance to hypoxic cellular injury and the amount of lactate generated and of glucose consumed by the cells. Thus, the cells with the lowest lactate dehydrogenase efflux (and highest glucose supplementations) had medium lactate concentrations as high as 32-36 mM. These concentrations of lactate are approximately double the reported threshold concentration of lactate considered to produce cellular necrosis in in vivo models of hypoxic injury, primarily in mature animals. The data raise the possibility that hypoxic injury to differentiating glia can be prevented or ameliorated by increase in glucose availability. (Pediatr Res 27: 186-190, 1990)
\end{abstract}

Abbreviations

DMEM, Dulbecco's modified Eagle's medium LDH, lactate dehydrogenase

Hypoxic-ischemic brain injury incurred in the perinatal period is an extremely important clinical problem. This form of brain injury accounts for the largest proportion of the major nonprogressive neurologic deficits manifested in infancy and childhood under the rubrics, cerebral palsy and mental retardation (1). In recent years a large amount of research has been directed toward

Received August 7, 1989; accepted October 10, 1989.

Correspondence and reprint requests Dr. Joseph J. Volpe, Department of Pediatrics, Washington University School of Medicine, St. Louis Children's Hospital, 400 S. Kingshighway Blvd. St. Louis, MO 63110.

Supported by Grant R01-HD-07464 from the National Institutes of Health (J.J.V.) elucidation of the mechanisms of neuronal death with hypoxia. Indeed studies of neurons in cell cultures $(2,3)$, as well as in other experimental models (4), have emphasized the importance of excitatory amino acid neurotransmitters in the mediation of hypoxic neuronal death. However, relatively little work has been directed toward elucidation of mechanisms of hypoxic death of glia, especially developing glia. The particular importance of this research for the neonatal period is related to the fact that the dominant neuropathology in the human premature infant subjected to hypoxic-ischemic insult is not neuronal injury but rather injury to periventricular white matter, rich in developing glia but devoid of neurons (1). Neuropathologic data indicate that the glial cell is the particular target of such hypoxic injury $(5,6)$. The particular glial cell type(s) most affected are not yet known conclusively.

In this study we use a model of developing glial cells, i.e. primary glial cell cultures derived from newborn rat brain. Although containing both developing astrocytes and oligodendroglia, these cultures are composed of approximately $90-95 \%$ astrocytes, which undergo rapid differentiation in the 3rd wk in culture (see "Materials and Methods"). We undertook this study with three major objectives. First, because of a recent report that fully mature astrocytes exhibit no major signs of cell injury for as long as $12 \mathrm{~h}$ of hypoxia (7), we wished to determine the relative vulnerability of differentiating astrocytes to duration of hypoxia. Second, because in a variety of in vivo models of hypoxicischemic injury there is controversy regarding whether glucose supplementation is beneficial or deleterious (8-17), we studied the effect of exogenous glucose levels on vulnerability to hypoxia. Third, because in a variety of in vivo models of hypoxic-ischemic injury there is controversy regarding the role of high lactate levels in the mediation of cell death $(8,10,13,15,18-21)$, we determined the relation of extracellular lactate levels to the degree of hypoxic astrocytic injury.

\section{MATERIALS AND METHODS}

Materials. Newborn Sprague-Dawley rats were purchased from Sasco, Inc. (Omaha, NE). All chemicals were obtained from Sigma Chemical Co. (St. Louis, MO). Tissue culture flasks and other disposable culture materials were from Becton-Dickinson (Oxnard, CA) and from Corning (Corning, NY), except for Plastek culture dishes which were obtained from Tekmat Corp., (Ashland, MA). Nylon meshes were supplied by Small Parts, Inc. (Miami, FL). Tissue culture media were obtained from the Tissue Culture Support Center (Washington University Medical School (St. Louis, MO). FCS was purchased from HyClone (Logan, UT).

Cell culture. Primary glial cultures of the cerebral hemispheres of newborn rats were prepared by a modification of earlier methods (22-24), essentially as previously described (25). After decapitation, the brains of the newborn rats were removed to sterile Petri dishes containing a 1:1 mixture of PBS $(\mathrm{pH} 7.4)$ and 
DMEM at $37^{\circ} \mathrm{C}$. With the assistance of a dissecting microscope, the cerebellar hemispheres, brainstem, and meninges were removed and discarded. The cerebral hemispheres were mechanically dissociated by sequential passage through sterile nylon monofilament mesh with pore sizes of 125,37 , and $20 \mu \mathrm{m}$, respectively. The dissociated cells were suspended in sufficient volume of DMEM with $10 \%$ FCS to yield a ratio of one brain to $9 \mathrm{~mL}$ of cell suspension. The cell suspension was transferred in $3-\mathrm{mL}$ aliquots to $25-\mathrm{cm}^{2}$ Plastek tissue dishes. The cultures were incubated at $37^{\circ} \mathrm{C}$ in $95 \%$ air $/ 5 \% \mathrm{CO}_{2}$ and $95 \%$ humidity. The culture medium was first changed after 3-4 d in culture and subsequently three times per week with DMEM containing $10 \%$ FCS. The cultures were used for experiments on the 18th $\mathrm{d}$ in culture.

The composition of these glial primary cultures has been shown to be approximately $90-95 \%$ astroglial, by immunocytochemical and ultrastructural techniques (24, 26-29). The remaining cells are oligodendroglia. Neurons are absent. Study of such enzymatic markers as glutamine synthetase for astrocytes and $2^{\prime}, 3^{\prime}$-cyclic nucleotide $3^{\prime}$-phosphohydrolase for oligodendroglia by ourselves $(30,31)$ and by others $(24,32,33)$ has shown that these expressions of glial differentiation increase most rapidly during the $3 \mathrm{rd}$ wk in culture. For that reason, the experiments described herein were carried out on cells grown for $18 \mathrm{~d}$ in culture.

In vitro model of hypoxia. The in vitro model of hypoxia was similar to that described by $\mathrm{Yu}$ et al. (7). Thus, culture dishes were placed in a humidified modular incubator chamber (Billups-Rothenberg, Inc., Del Mar, CA) that was purged with $95 \%$ $\mathrm{N}_{2} / 5 \% \mathrm{CO}_{2}$ for $10 \mathrm{~min}$ at $12 \mathrm{~L} / \mathrm{min}$ and sealed. $\mathrm{Yu}$ et al. (7) showed that purging with this gaseous mixture at $10 \mathrm{~L} / \mathrm{min}$ for $10 \mathrm{~min}$ results in an atmosphere with undetectable oxygen. The incubation medium was fresh DMEM with varying concentrations of glucose, as indicated, which also had been bubbled with $95 \% \mathrm{~N}_{2} / 5 \% \mathrm{CO}_{2}$ at $1.0 \mathrm{~L} / \mathrm{min}$ for $5 \mathrm{~min}$. The chamber was placed inside a standard incubator at $37^{\circ} \mathrm{C}$ for the times indicated in "Results." Control cultures were incubated in identical media under aerobic conditions.

In the experiments described in "Results," the media and surviving cells were collected immediately after the prescribed period of hypoxia or normoxia for the assays. In either case, after the media were collected, the cells were washed three times with Tris- $\mathrm{NaCl}(\mathrm{pH} \mathrm{7.40)}$. One $\mathrm{mL}$ of $50 \mathrm{mM}$ Tris- $\mathrm{HCl}(\mathrm{pH} 7.50)$ then was added to the flasks and the cells were collected by scraping with a rubber policeman. (The medium was centrifuged to sediment detached cells, although in several pilot experiments LDH activity of the medium before and after centrifugation was virtually identical.) Cells and media, were then disrupted in a polytron homogenizer for $20 \mathrm{~s}$ before performing assays for $\mathrm{LDH}$ activity in the cells and media; for lactate concentration in the media, and for total protein content in the cells.

$L D H$. LDH activity of the cell homogenates and incubation media were determined immediately after collection. LDH activity was measured spectrophotometrically with pyruvate and NADH in a phosphate buffer according to the method of Bergmeyer and Bernt (34). One unit of LDH activity is defined as the amount of enzyme that catalyzes the formation of $1 \mu \mathrm{mol}$ of $\mathrm{NADH} / \mathrm{min}$.

Percent LDH efflux into the media (\% LDH efflux) was calculated for each of the hypoxic experimental and the normoxic control conditions by the following formula:

$\frac{\text { LDH activity of media }}{\text { total LDH activity (cells and media) }} \times 100 \%$

$=\% \mathrm{LDH}$ efflux

For each experimental condition, the percent LDH efflux reported is the difference between the percent LDH efflux of the hypoxic cultures and the percent LDH efflux of the normoxic control cultures. The percent LDH efflux of the normoxic control cultures at all concentrations of glucose studied was consistently very low, i.e. generally $1-3 \%$. In pilot experiments, percent LDH efflux was shown to be an excellent correlate of cell death, determined either morphologically or by measurement of total protein derived from cells remaining on the surface of the flasks. Koh and Choi (35) similarly have demonstrated the value of LDH efflux in the quantitation of cortical neuronal injury in cell culture.

Lactate and glucose determinations. The lactate concentration $(\mu \mathrm{mol} / \mathrm{mL})$ of the medium was determined spectrophotometrically by the method of Gutman and Wahlefeld (36). The glucose concentration $(\mu \mathrm{mol} / \mathrm{mL})$ of the medium was determined spectrophotometrically by the method of Bergmeyer et al. (37).

Total protein content. The total protein content of the cultures was determined by the method of Bradford (38).

\section{RESULTS}

Effect of hypoxia on LDH efflux. Initially we evaluated the effect of hypoxia on the glial cells as a function of duration of hypoxia at two concentrations of glucose in the culture medium (Fig. 1). Hypoxia had no apparent effect on the cells during the first $6 \mathrm{~h}$, but by $24 \mathrm{~h}$ of hypoxia cells in $5.6 \mathrm{mM}$ glucose, an approximately physiologic concentration, were strikingly af fected, as manifested by LDH efflux of $80 \%$. Notably, however, increase of medium glucose to $25 \mathrm{mM}$ totally protected the cells during $24 \mathrm{~h}$ of hypoxia.

The phase microscopic appearance of the cultures reflected the LDH data (Fig. 2). Thus, control cultures in $5.6 \mathrm{mM}$ glucose and aerobic conditions exhibited the typical appearance of a predominant bed layer of phase-light, epitheloid cells characteristic of astrocytes, upon which are a much smaller number of phase-dark cells characteristic of oligodendroglia (24) (Fig. 2A). After $24 \mathrm{~h}$ of hypoxia and $5.6 \mathrm{mM}$ glucose, there is widespread disintegration of cells (Fig. $2 B$ ). [After $2 \mathrm{~h}$ of hypoxia and 5.6 $\mathrm{mM}$ glucose, cellular morphology was clearly distorted, with swelling of processes and vacuolization of cytoplasm (not shown).] In contrast, after $24 \mathrm{~h}$ of hypoxia and $25 \mathrm{mM}$ glucose, no appreciable change in morphology can be identified (Fig. 2C). Moreover, total cellular protein content in the latter cultures was not different from that in the normoxic cultures (data not shown).

Effect of glucose on hypoxia-induced LDH efflux. We next evaluated the concentration dependence of the protective effect of glucose on the LDH efflux caused by $24 \mathrm{~h}$ of hypoxia (Fig. 3). A striking concentration dependence of the protective effect of

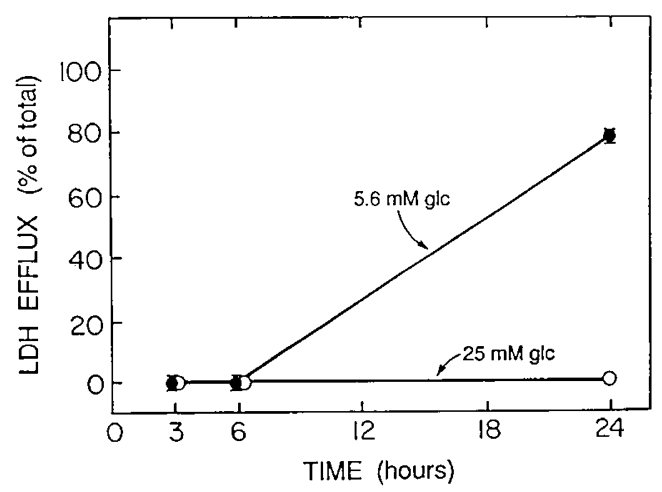

Fig. 1. Effect of hypoxia on LDH efflux. Primary cultures of developing glia were obtained from dissociated cerebral hemispheres of newborn rats and grown in culture for $18 \mathrm{~d}$ (see "Materials and Methods"). At that time the cultures were placed in fresh DMEM with the indicated concentrations of glucose $(\mathrm{glc})$, incubated in $95 \%$ nitrogen $/ 5 \% \mathrm{CO}_{2}$ for the indicated times, and LDH efflux determined as described in "Materials and Methods." Values are means \pm SD of separate determinations performed on three cultures. Essentially identical results were obtained in four separate experiments. 

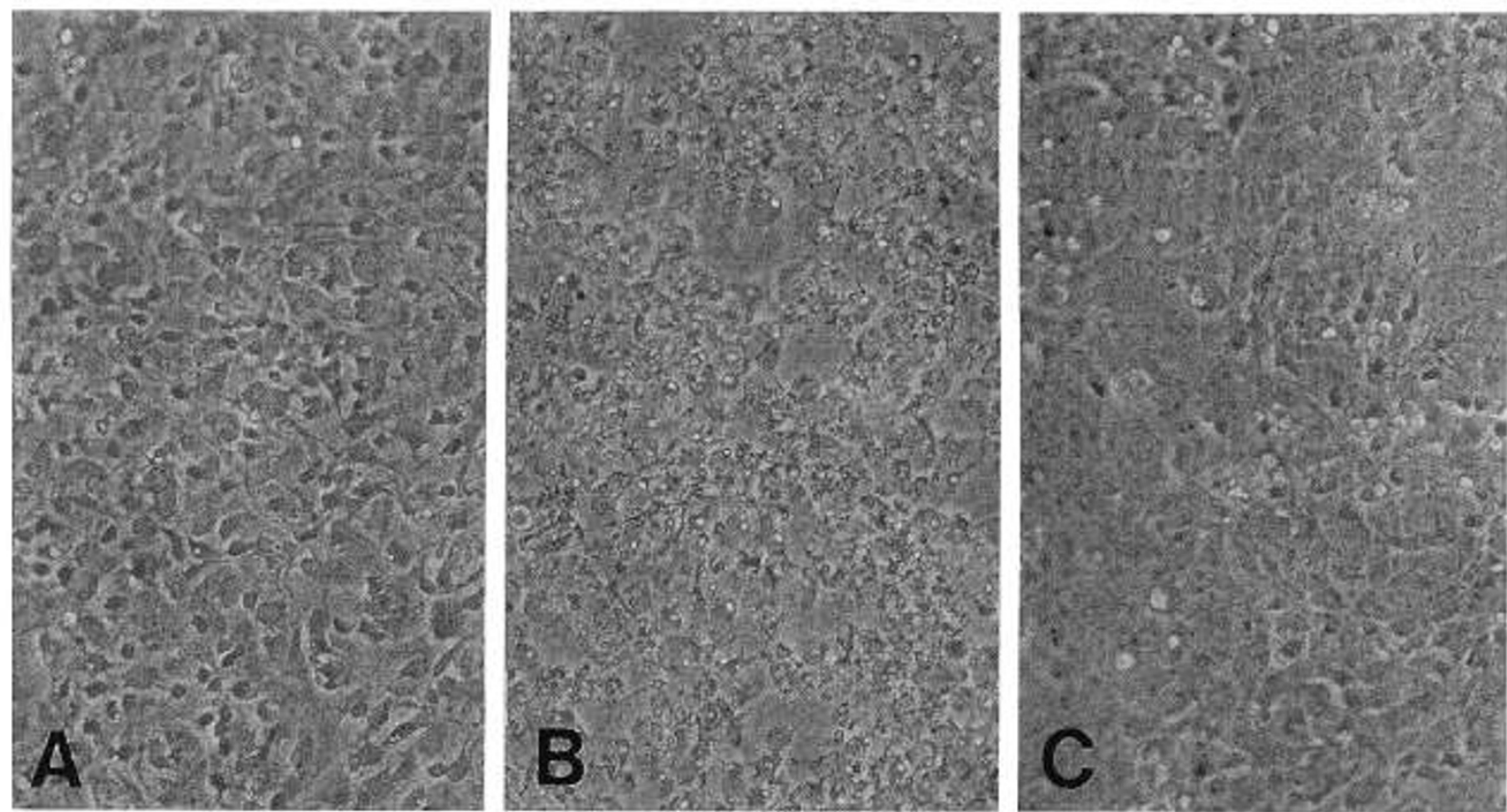

Fig. 2. Phase-microscopic appearances of $18-\mathrm{d}$ glial cultures that have been grown for $24 \mathrm{~h}$ in fresh DMEM and under the following conditions: $A$, $5.6 \mathrm{mM}$ glucose, normoxia ( $95 \%$ air $/ 5 \% \mathrm{CO}_{2}$ ) (control); $B, 5.6 \mathrm{mM}$ glucose, hypoxia $\left(95 \%\right.$ nitrogen $/ 5 \% \mathrm{CO}_{2}$ ); and $C, 25 \mathrm{mM}$ glucose, hypoxia $\left(95 \%\right.$ nitrogen $\left./ 5 \% \mathrm{CO}_{2}\right)$. The cultures were examined by phase-contrast microscopy $(\times 100)$.

glucose was apparent, such that concentrations of 5.6 and 10 $\mathrm{mM}$ were associated with $80-90 \% \mathrm{LDH}$ efflux, whereas a concentration of $15 \mathrm{mM}$ glucose totally prevented hypoxia-induced LDH efflux.

To ensure that the striking beneficial effect of $15 \mathrm{mM}$ glucose did not reflect simply an osmotic effect and to evaluate the possibility that other glycolytic intermediates might also protect the glial cells, we added to hypoxic cultures (and normoxic controls) either $10 \mathrm{mM}$ pyruvate, fructose-1,6-diphosphate, dihydroxyacetone phosphate, sucrose, or sorbitol in addition to $5.6 \mathrm{mM}$ glucose. No protective effect was observed with any of the additions (data not shown). The lack of protective effect of fructose-1,6-diphosphate is unlike observations made with fully differentiated astrocytes (39).

Relation of lactate concentration to $\mathrm{LDH}$ efflux of hypoxic cells. Because studies of ischemic animal models (derived principally from mature animals) suggest that high lactate concentrations may mediate hypoxic cell death and that there is a critical threshold of approximately 16-20 $\mathrm{mM}$ lactate above which cell death occurs $(8,18-20)$, we evaluated the relation of medium lactate concentrations to LDH efflux of cells made hypoxic. Thus, cells were exposed to $24 \mathrm{~h}$ of hypoxia in various concentrations of glucose (Fig. 4). Whereas lactate concentrations in the culture medium of control cells did not exceed a concentration of approximately $12 \mathrm{mM}$, lactate concentrations in cells made hypoxic increased markedly as a function of the glucose concentration in the medium. Indeed, peak concentrations of lactate (32-36 mM) were achieved at medium glucose concentrations (15-25 mM) that totally protected the cells from hypoxia (compare Fig. 3). Thus, in this model system cells least affected by hypoxia were exposed to the highest levels of lactate.

As a measure of glucose utilization, we quantitated the glucose concentration remaining in the medium after the $24 \mathrm{~h}$ of hypoxia and subtracted this quantity from the starting concentration to determine the amount of glucose consumed. The values for glucose utilization were, for flasks in $3,5.6,10,15$ and $25 \mathrm{mM}$ glucose; $9,17,30,44,55 \mu \mathrm{mol}$, respectively, for the 24 -h period. Thus, increasing glucose utilization occurred in concert with increasing lactate production.

The $\mathrm{pH}$ of the medium after $24 \mathrm{~h}$ of hypoxia did not differ

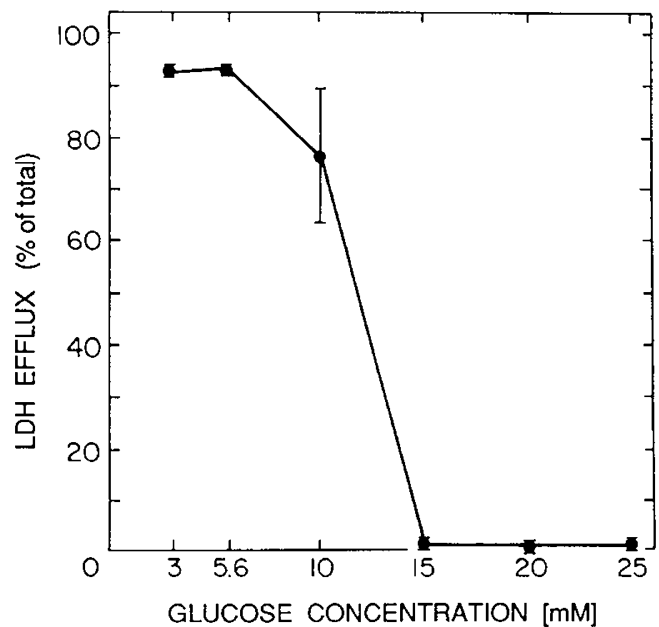

Fig. 3. Effect of glucose on hypoxia-induced LDH efflux. Primary cultures were grown for $18 \mathrm{~d}$ and subjected to $24 \mathrm{~h}$ of hypoxia, as described in the legend to Figure 1, with the indicated concentrations of glucose in the culture medium. Values are means $\pm \mathrm{SD}$, as described in the legend to Figure 1. Essentially identical results were obtained in three separate experiments.

from the $\mathrm{pH}$ of the medium of control flasks at medium glucose concentrations below $15 \mathrm{mM}$ (data not shown). The lowest $\mathrm{pH}$ in hypoxic flasks, 6.70 , was observed at the highest medium glucose concentration $(25 \mathrm{mM})$.

\section{DISCUSSION}

We addressed the effects of hypoxia on differentiating glial cells, primarily astrocytes. That our data reflect effects of hypoxia on differentiating astrocytes rather than oligodendroglia relates not only to the marked predominance of astrocytes in these glial primary cultures but also to our use of LDH efflux as a marker for hypoxic injury. Thus, $\mathrm{LDH}$ has been shown to be a major constituent of astrocytes, but not oligodendrocytes in glial primary cultures (40). The major findings of the study, therefore, 


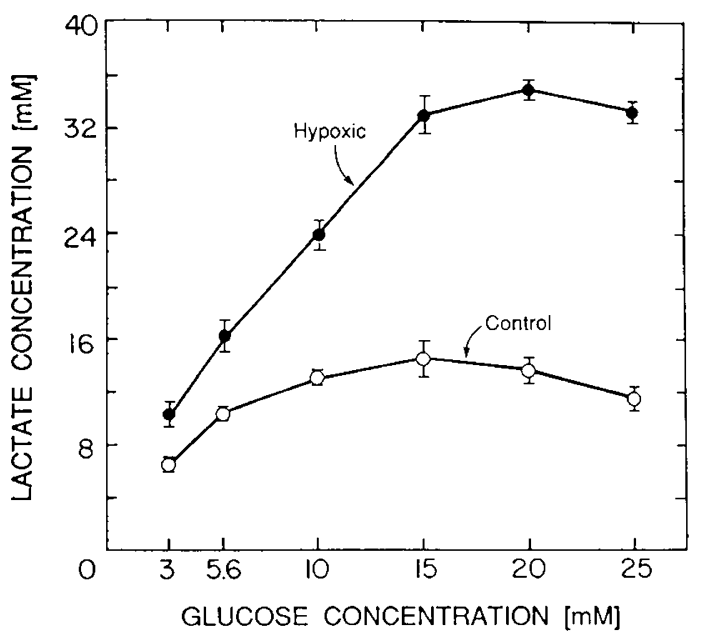

Fig. 4. Relation of lactate concentration in the culture medium after $24 \mathrm{~h}$ of hypoxia to the concentration of glucose in the culture medium (at the onset of hypoxia). The conditions of the experiment were identical to those described in the legend to Figure 2. Values are means \pm SD as described in the legend to Figure 1. Essentially identical results were obtained in three separate experiments.

relate to the relative vulnerability of differentiating astrocytes to hypoxia, the effect of exogenous glucose levels on this vulnerability, and the relation of medium lactate concentrations to hypoxic astrocytic injury.

Concerning the relative vulnerability of the differentiating astrocytes contained in these primary cultures to hypoxia, it is clear that these cells can tolerate hours of hypoxia with no effect on cellular integrity, as assessed by LDH efflux or morphologic appearance. This relative resistance of the differentiating astrocytes to hypoxia contrasts with the sensitivity of cultured neurons, which exhibit severe injury after several hours $(41,42)$. Nevertheless, after $24 \mathrm{~h}$ of hypoxia in medium containing 5.6 $\mathrm{mM}$ glucose, the astrocytes do exhibit severe cellular injury, manifested by LDH efflux of $80-90 \%$ and by morphologic evidence for widespread cellular disintegration. The finding of relative resistance of differentiating astrocytes to hypoxic injury for many hours in an approximately physiologic concentration of $5.6 \mathrm{mM}$ glucose is similar to that reported in $7.5 \mathrm{mM}$ glucose for fully mature cultured astrocytes (grown in culture for more than 4 wk and treated continuously with dibutyryl cyclic AMP after $2 \mathrm{wk}$ in culture to promote and maintain differentiation) (7).

The beneficial effect of elevation of medium levels to $15-25$ $\mathrm{mM}$ regarding hypoxic astrocytic injury is dramatic and not previously described. Thus, the differentiating astrocytes tolerated $24 \mathrm{~h}$ of hypoxia with no increase in LDH efflux above the minimal control values when the medium glucose level was 15 $\mathrm{mM}$ or more. This protective effect of elevated glucose levels is reminiscent of that shown in developing animal models of hypoxia and/or ischemia $(15,16,43,44)$. Moreover, the beneficial effect of increased glucose levels as shown in the current experiments and in the experiments with developing animals is unlike the deleterious effect of increased glucose observed in mature animal models of hypoxia and/or ischemia (8-13). The mechanisms underlying the beneficial effect of glucose in our experiments with differentiating glia and in experiments with developing animals are unclear, as are the mechanisms for the differences in the effects of glucose supplementation between immature and mature animals. Factors of potential importance include differences in glycogen stores, glucose transport and utilization, rates of utilization of high energy phosphate levels, and lactate accumulation and/or utilization, but more data are needed to define the relative importance of each of these in each system.
Concerning the relation of lactate concentrations to hypoxic astrocytic injury, our data indicate that lactate levels far in excess of the 16-20 mM threshold considered important for cellular death in in vivo models of hypoxia $(8,18-20)$ are compatible with complete protection of differentiating astrocytes. Indeed, the demonstration that high lactate levels are associated with the high medium glucose levels that lead to protection from hypoxia suggests that glucose utilization via glycolysis is the principal means by which the protective effect of glucose occurs. Our demonstration that the quantity of glucose consumed during the $24 \mathrm{~h}$ of hypoxia increased nearly linearly with quantity of glucose in the starting medium, and similarly with the quantity of lactate measured in the medium after the $24 \mathrm{~h}$ of hypoxia, strongly supports this conclusion. Moreover, our findings are not consistent with the concept of a threshold concentration of lactate of approximately $16-20 \mathrm{mM}$ that is considered to mediate hypoxic cell death in in vivo models of ischemic injury to brain. Although most such models involve mature brain, one involves developing brain [fetal sheep (20)] and glial-enriched regions thereof [cerebral white matter (20)]. One explanation for the difference between our findings with differentiating astrocytes in culture and those derived from the in vivo models is the possibility of an artificially greater buffering capacity of the culture medium compared to the potentially more limited buffering capacity of the extracellular space in brain in vivo. In this regard, there is evidence to suggest that it is not lactate per se that is injurious but rather the lowered $\mathrm{pH}$ associated with its accumulation (45, 46). In our experiments, the lowest $\mathrm{pH}$, which was observed in the flasks supplemented with $25 \mathrm{mM}$ glucose, is only slightly above that necessary to produce tissue injury in most animal models (42), but was compatible with complete protection of the developing glia in our system.

Clearly further data are needed on these issues, because the possibility that glucose supplementation could be beneficial in prevention of hypoxic injury in developing brain, suggested initially by studies of animal models, and now by our studies at the cellular level, has important clinical implications. Thus, available evidence indicates that unlike the typically intrauterine hypoxic injury of the full-term infant, hypoxic brain injury in the premature infant occurs postnatally, during the neonatal period (1), when such preventative intervention as glucose supplementation could be attempted more readily. Nevertheless, in the absence of data concerning the effect of such supplementation on brain $\mathrm{pH}$ and lactate levels, potentially obtainable in the human infant by nuclear magnetic resonance spectroscopy (47), recommendation for such supplementation cannot be made with certainty about its safety.

Acknowledgment. Sherri Vogt provided expert technical assistance.

\section{REFERENCES}

1. Volpe JJ 1987 Neurology of the Newborn, 2nd ed. WB Saunders, Philadelphia, pp 160-280

2. Rothman SM, Olney JW 1986 Glutamate and the pathophysiology of hypoxicischemic brain damage. Ann Neurol 19:105-111

3. Choi DW 1988 Glutamate neurotoxicity and diseases of the nervous system. Neuron 1:623-634

4. Johnston MV, McDonald JW, Silverstein F 1988 Role of synaptic mechanisms in hypoxic-ischemic brain injury and birth defects. In: Swann JW, Messer A (eds) Disorders of the Developing Nervous System: Changing Views on Their Origins, Diagnoses, and Treatments. Alan R. Liss, Inc., New York, pp $69-$ 92

5. Larroche JC 1977 Developmental Pathology of the Neonate. Elsevier/NorthHolland Biomedical Press, Amsterdam, pp 399-408

6. Leviton A, Gilles FH 1983 The epidemiology of the perinatal telencephalic leukoencephalopathy characterized by hypertrophic astrocytes and acutely damaged glia. In: Gilles FH, Leviton A, Dooling EC (eds) The Developing Human Brain: Growth and Epidemiologic Neuropathology. John Wright/ PSG Inc, Boston, pp 296-303

7. Yu ACH, Gregory GA, Chan PH 1989 Hypoxia-induced dysfunctions and injury of astrocytes in primary cell cultures. J Cereb Blood Flow Metab 8:2028

8. Myers RE, Wagner RK, deCourten-Myers GM 1983 Brain metabolic and 
pathologic consequences of asphyxia: role played by serum glucose concentrations. In: Milunsky A, Friedman E, Gluck L (eds) Advances in Perinatal Medicine, Vol 3. Plenum, New York, pp 67-115

9. Voll CL, Auer RN 1988 The effect of postischemic blood glucose levels on ischemic brain damage in the rat. Ann Neurol 24:638-646

10. Pulsinelli WA, Waldman S, Rawlinson D, Plum F 1982 Moderate hyperglycemia augments ischemic brain damage: a neuropathologic study in the rat Neurology 32:1239-1246

11. Rehncrona S, Rosen I, Siesjo BK 1981 Brain lactic acidosis and ischemic cell damage: I. Biochemistry and neurophysiology. J Cereb Blood Flow Metab 1:297-311

12. Siemkowicz E, Hansen AJ 1978 Clinical restitution following cerebral ischemia in hypo-, normo-, and hyperglycemic rats. Acta Neurol Scand 58:1-8

13. Welsh FA, Ginsberg MD, Rieder W, Budd WW 1980 Deleterious effect of glucose pretreatment on recovery from diffuse cerebral ischemia in the cat. II. Regional metabolite levels. Stroke 11:355-363

14. Zasslow MA, Pearl RG, Shuer LM, Steinberg GK, Lieberson RE, Larson Jr CP 1989 Hyperglycemia decreases acute neuronal ischemic changes afte middle cerebral artery occlusion in cats. Stroke 20:519-523

15. Vannucci RC, Vasta F, Vannucci SJ 1987 Cerebral metabolic responses of hyperglycemic immature rats to hypoxia-ischemia. Pediatr Res 21:524-529

16. Voorhies TM, Rawlinson D, Vannucci RC 1986 Glucose and perinatal hypoxic-ischemic brain damage in the rat. Neurology 36:1115-1118

17. Paljarvi L, Rehncrona S, Soderfeldt B, Olsson Y, Kalimo H 1983 Brain lactic acidosis and ischemic cell damage: quantitative ultrastructural changes in capillaries of rat cerebral cortex. Acta Neuropathol 60:232-240

18. Ting P, Yamaguchi S, Bacher JD, Killens RI, Myers RE 1983 Hypoxicischemic cerebral necrosis in midgestational sheep fetuses: physiologic correlations. Exp Neurol 80:227-245

19. Plum F 1983 What caused infarction in ischemic brain?: the Robert Wartenberg lecture. Neurology 33:222-233

20. Wagner KR, Ting P, Westfall MV, Yamaguchi S, Bacher JD, Myers RE 1986 Brain metabolic correlates of hypoxic-ischemic cerebral necrosis in midgestational sheep fetuses: significance of hypotension. J Cereb Blood Flow Metab 6:425-434

21. Welsh FA, Vannucci RC, Brierley JB 1982 Columnar alterations of NADH fluorescence during hypoxia-ischemia in immature rat brain. J Cereb Blood Flow Metab 2:221-228

22. Booher J, Sensenbrenner M 1972 Growth and cultivation dissociated neurons and glial cells from embryonic chick, rat and human brain in flask cultures. Neurobiology 2:97-105

23. Hertz L, Juurlink BHJ, Fosmark H, Schousboe A 1982 Methodological appendix: astrocytes in primary cultures. In: Pfeiffer $S$ (ed) Neuroscience Approached Through Cell Culture, Vol I. CRC Press, Boca Raton, FL, pp 175186

24. Hertz L, Juurlink BHJ, Szuchet S 1985 Cell cultures. In: Lajtha A (ed) Handbook of Neurochemistry, Vol 8. Plenum Press, New York, pp 603 661

25. Langan TJ, Volpe JJ 1987 Cell cycle-specific requirement for mevalonate, but not for cholesterol for DNA synthesis in glial primary cultures. $J$ Neurochem 49:513-521

26. Raff MC, Fields KF, Hakomori S, Mirsky R, Pruss RM, Winter J 1979 Celltype specific markers for distinguishing and studying neurons and the major classes of glial cells in culture. Brain Res 174:283-308

27. Manthorpe M, Adler R, Varon S 1979 Development, reactivity and GFA immunofluorescence of astroglia-containing monolayer cultures from rat cerebrum. J Neurocytol 8:605-621
28. Olson JE, Holtzman D 1980 Respiration in rat cerebral astrocytes from primary culture. J Neurosci Res 5:497-506

29. Ebersolt C, Perez M, Bockaert J 1981 Neuronal, glial and meningeal localization of neurotransmitter-sensitive adenylate cyclase in cerebral cortex of mice. Brain Res 213:139-150

30. Wernicke JF, Volpe JJ 1986 Glial differentiation in dissociated cell cultures of neonatal rat brain: noncoordinate and density-dependent regulation of oligodendroglial enzymes. J Neurosci Res 15:39-47

31. Ishii S, Volpe JJ 1988 Dolichol-linked oligosaccharide and glycoprotein biosyntheses in glial cells in primary culture: development and enzymatic correlates. J Neurosci Res 20:463-472

32. Pfeiffer SE, Barbarese E, Bhat S 1981 Noncoordinate regulation of myelinogenic parameters in primary cultures of dissociated fetal rat brain. J Neurosci Res 6:369-380

33. Bansal R, Pfeiffer SE 1985 Developmental expression of $2^{\prime}, 3^{\prime}$-cyclic nucleotide $3^{\prime}$-phosphohydrolase in dissociated fetal rat brain cultures and rat brain. J Neurosci Res 14:21-34

34. Bergmeyer HU, Bernt E 1974 Lactate dehydrogenase and UV-assay with pyruvate and NADH. In: Bergmeyer HU (ed) Methods of Enzymatic Analysis, Vol 2. Verlag Chemie International, Deerfield Beach, FL, pp 574-579

35. Koh JY, Choi DW 1987 Quantitative determination of glutamate mediated cortical neuronal injury in cell culture by lactate dehydrogenase efflux assay. J Neurosci Methods 20:83-90

36. Gutman I, Wahlefeld AW 1974 L-(+)-lactate determination with lactate dehydrogenase and NAD. In: Bergmeyer HU (ed) Methods of Enzymatic Analysis, Vol 3. Verlag Chemie International, Deerfield Beach, FL, pp 1464 1468

37. Bergmeyer HU, Bernt E, Schmidt F, Stork H 1974 D-glucose: determination with hexokinase and glucose-6-phosphate dehydrogenase. In: Bergmeyer HU (ed) Methods of Enzymatic Analysis, Vol 3. Verlag Chemie International, Deerfield Beach, FL, pp 1196-1201

38. Bradford M $1976 \mathrm{~A}$ rapid and sensitive method for the quantitation of microgram quantities of protein utilizing the principle of protein-dye binding. Anal Biochem 72:248-254

39. Gregory GA, Yu ACH, Chan PH 1989 Fructose-1,6-bisphosphate protects astrocytes from hypoxic damage. J Cereb Blood Flow Metab 9:29-34

40. Warringa RAJ, van Berlo MF, Klein W, Lopes-Cardozo M 1988 Cellular location of glutamine synthetase and lactate dehydrogenase in oligodendrocyte-enriched cultures from rat brain. J Neurochem 50:1461-1468

41. Romijn HJ, Ruijter JM, Wolters PS 1988 Hypoxia preferentially destroys GABAergic neurons in developing rat neocortex explants in culture. Exp Neurol 100:332-340

42. Kim SU 1975 Brain hypoxia studied in mouse central nervous system cultures. I. Sequential cellular changes. Lab Invest 33:658-665

43. Holowach-Thurston J, Hauhart RE, Jones EM 1974 Anoxia in mice: reduced glucose in brain with normal or elevated glucose in plasma and increased survival after glucose treatment. Pediatr Res 8:238-243

44. Dawes GS, Jacobson HN, Mott JC, Shelley HJ, Stafford A 1963 The treatmen of asphyxiated mature foetal lambs and rhesus monkeys with intravenous olucose and sodium carbonate. J Physiol 169:167-173

45. Norenberg MC, Mozes LW, Gregorios JB, Norenberg LB 1987 Effects of lactic acid on astrocytes in primary culture. J Neuropathol Exp Neurol 46:154 166

46. Hakim AM, Shoubridge EA 1989 Cerebral acidosis in focal ischemia. Cerebro vasc Brain Metab Rev 1:115-132

47. Bottomley, PA 1989 Human in vivo NMR spectroscopy in diagnostic medicine: clinical tool or research probe? Radiology 170:1-15 